\title{
COMMENTS
}

\section{LEGAL IMPLICATIONS OF PSYCHOLOGICAL RESEARCH WITH HUMAN SUBJECTS}

$P_{\text {sychiatrists and psychologists have recently evinced concern over }}$
the legal implications of psychological research with human subjects.
Their concern is understandable, especially as it pertains to liability for
damages, for the environment in which such human experimentation is
pursued may be aptly termed extralegal in that legal bounds have not
been delineated by judicial or legislative pronouncements. ${ }^{2}$ To a dis-

${ }^{1}$ American Psychological Ass'N, Ethical Standards of Psychologists 11 3-24 (1953); Berg, The Use of Human Subjects in Psychological Research, 9 AM. PsYchol. ro8 (1954); Rogers, Persons or Science? A Philosophical Question, ro AM. Psychol. 267 (1955); Rogers, Some Issues Concerning the Control of Human Behavior, address to American Psychological Association Annual Meeting, Aug. 1956; Bressler, Silverman, Cohen \& Shmavonian, Research in Human Subjects and the Artificial Traumatic Neutrosis: Where Does Out Responsibility Lie?, I16 AM. J. PsychiATrX 522 (1959).

Current psychological research projects concerned with isolation and sensory deprivation, and involving the experimental manipulation of fundamental aspects of the mental. functioning of particular human beings, have emphasized the need to clarify the legalenvironment of psychological research with human subjects.

The Bio-Sciences Information Exchange, a clearinghouse for current research in the biological, medical, and psychological sciences which serves both government and nongovernment fund-granting agencies and investigators associated with recognized research institutions, has on file thirteen active notices of research projects submitted by psychiatrists and psychologists engaged in such studies.

Although these research projects differ in design and methodology and often employ varying techniques, either because of variations in their primary focus of interest or different theoretic frames of reference, their general purpose is the study of disruptive psychologic effects of environments which are void of direct human contact and which have an altered sensory input both as to pattern and quantity of stimuli.

The following statement is illustrative of the procedure followed in these experiments: "[The subjects] were then confined in a dark, light-proof, soundproof, cubiclelike room $(4 \times 9 \times 8 \mathrm{ft}$.) which contained only a bed. They wore gloves to which circular cardboard tubes were attached. These tubes extended from below the elbow to beyond the fingertips. Ear-plugs were used to reduce detection of noise of the Ss' own making. They were instructed to remain as quiet as possible since the intent was to reduce all sensory stimulation to as low a level as possible-hence the use of the somewhat inaccurnte term 'sensory deprivation.'" Vernon \& McGill, The Effect of Sensory Deprivation upon Rote Learning, 70 Aм. J. Psychol. 637 (1957).

9 "Reported cases have not yet considered modern controlled medical research, and have not yet established limits within which human research may be pursued." Ladimer, Legal and Ethical Implications of Medical Research on Human Beings 170 (1958) (unpublished thesis in The George Washington Law School Library) [hereinafter cited as Ladimer]. Irving Ladimer, S.J.D., former Assistant Chief, Office of Research Planning, National Institutes of Health, United States Public Health Service, recently served as Conference Secretary and Medico-Legal Consultant to the National Conference 
cipline which has experimented with human beings since first assuming a scientific posture, ${ }^{\mathbf{3}}$ the situation is indeed anomalous. The irony of this situation lies in the fact that in recent years it has been the federal government which has generously supported psychological research, both within its own laboratories and by contract and grant to colleges, study centers, and other institutions. ${ }^{4}$

That the problem of the proper conduct of psychological research has not been directly raised in a judicial forum may be explained by the fact that such research has seldom heretofore involved potential harm to the subject. ${ }^{5}$ However, when an investigation involves the experis

on the Legal Environment of Medical Science, University of Chicago.

"[W] hile human experimentation has accompanied the practice of medicine from times of antiquity, the current concept of medical research has not really been presented as such to the courts. As the courts have understood it, human experimentation has not been, nor is it now, legally recognized as a legitimate part of the physician's activities. ... The universal and long-standing recognition that research is essential to the advancement of medical. science and the newer recognition that some aspects of basic science cannot advance without it have led to a correct, although still extralegal, expansion of human experimentation. Curiously, such work, when well conceived and soundly conducted, is everywhere recognized as being properly within the ethical and moral concepts of our time; yet it remains outside legally. Legal inclusion will depend on an understanding of all the facets of the problem." Beecher, Experimentation in Man, I69 A.M.A.J. 461 (1959).

"No reported court decision has considered research specifically in terms of the right and liability of a trained professional to use a living patient or a normal subject as a means of discovering new knowledge not necessarily of direct benefit to that patient or subject. None of the cases that have actually come before the appellate courts have. involved a real scientist observing the proper precautions and giving primary consideration to the welfare of his patient." Sessoms, Guiding Principles in Medical Research Involving Humans, 32 A. Hosp. Ass'N J. 44, 6o (1958).

${ }^{3}$ Ladimer, at 8 .

'Ibid., citing Young \& Wilson, Govermment Sutpport of Extramutral Psychological Research: Fiscal Year 1956, i 1 AM. Psychol. 630 (1956), in which some idea is given of the magnitude of federally supported psychological research, most of which involves experimentation with human subjects: "In fiscal year 1956 (ending June 30, 1956) approximately 10.5 million dollars were obligated by some twenty departments and subdivisions of the Federal Government for the conduct of research in psychology and closely related areas. ... This total continues the trend toward regaining the high postwar level reached in fiscal 1953 (approximately 11 million dollars)."

"It has been proposed, however, that future experimentation be "far more realistic than it has been in the past," although the proponent is undecided as to how far one can go in a no-holds-barred type of research with human subjects. Letter From John C. Lilly, M.D., Executive Director, Communication Research Institute, U.S. Virgin Islands, to the Duke Law Journal, July 7, 1959, on file in Duke University Law Library. Dr. Lilly provocatively adds: "Even on a purely medical side it might pay tremendously to do courageous experiments pushing the boundaries on the moral and ethical things back a little more than they are at the present time. . . . Many diseases have their origin in stressful situations. Especially in the psychological sphere. At least this is the present 
mental manipulation of fundamental aspects of mental functioning of a particular human being, ${ }^{6}$ and thus creates the potential for serious injury, the possibility of the subject's seeking judicial redress for his injury is not so remote that speculative consideration of related legal problems is unwarranted.

If a legal action is brought against the scientific experimenter, its result will depend upon the existence of a privilege conferred on the experimenter by society, determined by balancing the risk of possible harm to the subject against the potential returns to society, ${ }^{7}$ and upon the legal efficacy of the subject's consent, the appraisal of which would be difficult due to circumstances of psychological research which may often preclude apprising him sufficiently of the possible risk of harm. ${ }^{8}$

theory. Experimental verification of such matters awaits courageous scientific work which is yet to he done."

- As in conceivable isolation and sensory deprivation studies.

${ }^{7}$ In a letter to the Duke Law Journal, dated May 27, 1959, on file in the Duke' University Law Library, George E. Ruff, Capt., USAF(MC), Chief, Stress \& Fatigue Section, Aero Medical Laboratory, Wright-Patterson Air Force Base, Ohio, states: "It seems apparent that reasons for justifying isolation research must become stronger as risks increase. We feel that the limited possibilities of danger in our work are more than outweighed by its potential returns. Both the need for data on personality structure and function and on environments important in space flight are more than enough to justify these particular experiments. Such reasons would probably not justify studies where a high percentage of the subjects might be harmed."

${ }^{8}$ The subject's having sufficient knowledge and comprehension of the elements of the subject matter involved as to enable him to make an understanding and enlightened decision "is often quite impossible ... for the complexities of essential medical research have reached the point where the full implications and possible hazards cannot always be known to anyone and are often communicable only to a few informed investigators and sometimes not even to them. Certainly the full implications of work to be done are often not really communicable to lay subjects." Beecher, supra note 2, at 473 .

Sufficient knowledge and comprehension on the part of the subject to enable him to make an enlightened decision are all the more difficult to achieve in the conduct of psychological research because: (I) Animal experimentation is only of limited usefulness in interpreting emotional and behavioral states. Ladimer, at 89. In fact, investigations of complex psychologic reactions, which are either lacking or not comprehensible in animals, require active initial participation by human subjects. Shimkin, The Problem of Experimentation on Human Beings: The Research Worker's Point of View, 117 ScIENCE 205, 207 (1953). (2) Pre-experimental instructions and information made available to the subject may be extremely important determinants of ultimate response. Ruff, Levy \& Thaler, Some Influences on Reaction to Reduced Sensory Input, Aero Medical Laboratory, Wright-Patterson Air Force Base, Ohio (unpublished manuscript on file in the Duke University Law Library); Cohen, Silverman, Bressler \& Shmavonian, Practical and Theoretic Difficulties in "Isolation" Studies, Psychophysiologic Laboratory, Duke University Medical Center (unpublished manuscript on file in the Duke University Law Library). Capt. George E. Ruff states im his letter, supra note 7, that: "Because the removal of external structuring increases the importance of subtle cues to the subject, I feel that it is impossible to discuss with the subject either the risks or any 
Further, if liability exists, the subject's recovery of damages will be affected both by the elements of loss or types of harm deemed compensable and by the measurement of these elements of loss. Determining the elements or the types of harm is complicated by the fact that harms of varying degrees of tangibility may result from the internal operation of psychic stimuli. ${ }^{9}$ The measurement of these elements of harm will also be difficult of solution due to the problem of assigning value to altered psychological functioning. The solution of this latter problem will be facilitated, however, by knowledge of the subject's pre-existing personality make-up, of the force and character of the stimulus, and of the subject's susceptibility to the stimulus. ${ }^{10}$

\section{LIABILITX ${ }^{11}$}

Legally, it is difficult to regard psychological experimentation as other than an intentional invasion of the subject's interest in peace of mind, an interest entitled to independent legal protection in the absence of a privilege conferred by society and the subject's consent.

When is an experimenter privileged? Conceptually, privilege creates an immunity which prevents the very existence of the tort. It signifies that the defendant has acted to further an interest of such social importance that he is entitled to protection from liability for the in-

other features of the experiment before it begins. Responsibility for whatever happens clearly rests upon the shoulders of the experimenter, so that one should use considerable discretion in choice of subjects and procedures for this kind of research." (3) Results of isolation experiments depend on the manipulation of experimental variables, and such experiments thus involve varying degrees of risk. On this point Capt. Ruff states: "In our studies ... factors which are threatening to the subject are miuimized. Since we do not feel that isolation is dangerous per se, chances of harm to the subject are low in our situation. On the other hand, by maximizing the conditions which produce anxiety, such experiments would have drastically different effects." (4) The implications of altered psychologic functioning may not be so appreciated by subjects of psychological experimentation as would the consequences which could result, for example, from participation in "live" polio vaccine experiments.

${ }^{8}$ There have been experiments in which a temporary abrogation of usual ego functioning has been introduced, producing in the subject what has been termed a temporary artificial traumatic neurosis which would not have emerged with the same intensity in ordinary circumstances. See Bressler, Silverman, Cohen \& Shmavonian, supra note 1 , at 525.

${ }^{10}$ See Ruff, Levy \& Thaler, supra note 8, at 5-10; Cohen, Silverman, Bressler \& Shmavonian, supra note 8 , at 4-23.

${ }^{11}$ Although the experimenter-subject relationship may be viewed as contractual, each party agreeing to perform in accordance with prearranged terms and obligations, implied and expressed, the question of liability is fundamentally a tort problem. The criminal responsibility of the experimenter is considered in Smith, Antecedent Grounds of Liability in the Practice of Surgery, 14 RocKY MT. L. REv. 233, 287 (1942); Ladimer at $120-3 \mathrm{x}$. 
jurious consequences of his act. His action is privileged because the public interest warrants it, and social policy will best be served by permitting it. Thus, the limits of the privilege are defined by current.ideas of what will most effectively promote the public welfare.

Fundamental to the question of liability, then, is whether the research program and the experimentation encompassed therein are of such paramount public concern that a privilege should be conferred upon the investigator. Legal acceptance of such a public policy would appear to depend upon the extent of its embodiment in law. ${ }^{12}$ Of this it has been said: ${ }^{13}$

Certain it is that the performance of an experiment involving serious consequences would have to be specifically, not generally, acceptable under law or associated with some public emergency or necessity ... or military requirement. There is no assurance, otherwise, that an agreement for voluntary participation, even with full knowledge, will insure non-liability.

Still, the disposition of the liability question can hardly rest on a privilege founded only on extrinsic policy factors, for nonconsensual privilege cannot extend to a situation in which, as here, the relationship is one of free association.

What is "legally sufficient" consent? Because consent of the injured party will ordinarily avoid liability for intentional interference with his interests, the nature of the consent which will have this insulating effect requires careful consideration.

A recent article ${ }^{14}$ on liability for medical experimentation contends that express consent to experimentation should bar tort recovery, citing as authority an early Illinois decision ${ }^{25}$ which held that, in order to constitute an effective defense, consent must be based on full disclosure of both the novelty of the procedure and the possible hazards involved. It has also been suggested that, where no social or scientific interest is involved, the requisite disclosure should be full and explicit, including the "impropriety of the experiment . . . to make the subject's consent enlightened submission."

Assuming that the subject thoroughly understands the hazards involved in the experiment and that there is no unequal bargaining, a research contract involving scientifically and morally acceptable research

\footnotetext{
${ }^{19}$ Bohlen, Consent as Affecting Civil Liability for Breaches of the Peace, 24 CoLvM. L. REv. 819 ( 1924$)$.

${ }^{13}$ Ladimer, at i 52 .

It Note, 40 Calif. L. REv. 159 (I952).

${ }^{15}$ Graham v. Doctor Pratt Inst., 163 IIl. App. 9 I (IgII).

${ }^{10}$ Smith, supra note I $\mathrm{I}$, at 287 .
} 
can stand against intentional interest-invasion. ${ }^{17}$ The practice followed by recognized research institutions, requiring a signed and witnessed agreement setting forth the aims, procedures, and possible risks involved in the research, seems to be the safest assurance and evidence of formal understanding following verbal explanation and questioning. ${ }^{18}$

The sufficiency of this agreement will depend upon the extent of subject enlightenment which is feasible under the circumstances of the experiment. ${ }^{19}$ In psychological research, pre-experimental instruction of the subject is often necessarily restricted because to inform the subject fully of the nature and purpose of the experiment may produce in him the unwanted variable of suggestibility and thereby impair the validity of the experiment's results. Moreover, subject enlightenment may be impossible where the subject does not truly understand the implications of altered psychologic functioning or otherwise fails to appreciate the risks to which he will be subjected. In these circumstances in which the consent of the subject may lack legal sufficiency, the experimenter thus chooses between jeopardizing the validity of his research and subjecting himself to liability for injuries to the subject.

Consent of the nature involved in the physician-patient relationship would seem to be clearly inadequate, because it is often inferred from the fact that the physician's efforts are directed to the maintenance of the patient's health for his benefit. ${ }^{20}$ In the experimenter-subject relationship, however, implied consent lacks legal sufficiency because the subject is not seeking the benefit of the experimenter's skills; in fact, he has little to gain from the relationship.

The preceding discussion has considered the possibility that litigation arising out of psychological experimentation may determine it to be an intentional invasion of interest. Allegations of negligence, or recklessness, for which the general rules of malpractice would be applicable, ${ }^{21}$ are conceivable as well.

Clearly, malpractice applies to the research scientist who fails to meet the controlling standards or guides governing the profession of scientific investigation. ${ }^{22}$ These standards or guides may appear subtle

\footnotetext{
${ }^{17}$ Ladimer, Ethical and Legal Aspects of Medical Research on Human Beings, $3 \mathrm{~J}$. Pub. L. 467,508 (1954).

${ }^{18}$ Research principles which guide the clinical research program at the Clinical Center of the National Institutes of Health are presented in an examination of some of the legal and moral aspects of drug research in Sessoms, supra note 2.

${ }^{19}$ See note 8 supra.

${ }^{20}$ Ladimer, at 154 ; Ladimer, supra note 17 , at $485,503-04$.

${ }^{21}$ Ladimer, supra note $\mathrm{I} 7$, at $503 .{ }_{23} I d$. at 486 .
} 
and elusive since the essence of research is novel and untried activity, ${ }^{23}$ but the means by which research is planned or undertaken and the safeguards employed are essentially analogous to those which guide the general practitioner.

These standards and guides may be derived from at least three sources: ${ }^{24}$

(x) formal and informal codes or guides of conduct suggested for application in the field of study and practice; ${ }^{25}$

(2) actual procedures employed by institutions and scientists of standing and repute; ${ }^{26}$ and

(3) applicable statutes and regulations. ${ }^{27}$

To the extent such standards and guides are available, some basis for determining proper legal action in each fact situation would exist.

Is assumption of risk a tenable defense? There are at least two different concepts of voluntary assumption of risk, involving different policies and different conditions for their application. ${ }^{28}$ In its primary sense the plaintiff's assumption of risk is only the counterpart of the defendant's lack of duty to protect the plaintiff from that risk. The defendant is not negligent because he creates a risk only to those who know about and desire to encounter the risk, and he is justified in reasonably thinking that no one will be subjected to the risk he creates unless the person wants to be. To the extent the experimenter-subject relationship is one of free association, then, the application of assumption of risk in this primary sense should relieve the experimenter of liability unless his belief that the subject knew about and desired the risk was an unreasonable one, or unless the experimenter's conduct creates a risk of such magnitude that liability should be imposed simply as a matter of public policy.

When plaintiff may be said to have assumed the risk created by

${ }^{23}$ Ibid. ${ }^{24}$ Ibid.

${ }^{20}$ E.g., American Psychologicai Ass'N, op. cit. supra note $\mathrm{I}$, even sets forth the ten principles for establishiug general rules of conduct in developing research programs as formulated in 1949 in the judgment of the Trials of War Crimmals before the Nuremberg Military Tribunals under Control Council Law No. ro, 2 The Medical Case 181 (r949).

${ }^{20}$ See note 18 supra.

${ }^{27}$ The opinion of the Attorney General of the State of New York, that there is no provision of law that would permit any form of research to be performed upon a patient confined in a state institution is one example. Ladimer, at $90 \mathrm{n.r8x}$. Rules governing the conduct of research in New York City hospitals are another example. Beecher, supra note 2, at $466 \mathrm{n} .23$.

${ }^{28}$ HARPER \& JAMES, TORTS $\$ 21.1$ (1956). 
defendant's breach of duty by knowingly encountering that risk without justification, then assumption of risk in this secondary sense (analytically, advertent contributory negligence) is an appropriate defense. However, is it a tenable one in this situation? Although the subject may have known what the experimenter intended to do and may have been willing to have this done to him, still, the subject may not have fully realized the risks involved. Mere knowledge of the facts which create the risk of harm is not enough unless there is a true appreciation of the nature and extent of the risk $;^{29}$ only then is the subject's assent given under circumstances which make it legally effective. The important point here, however, is that, in ascertaining whether the subject truly appreciated the risk of harm involved, it is inevitable that considerations of policy, depending on the result desired, will consciously or unconsciously influence the court's decision.

Further, and in contrast, where assumption of the risk in its secondary sense bars the subject from recovery because he acted unreasonably in encountering the risk under the circumstances, the court has the opportunity to consider policy factors in applying the standard of reasonableness to the particular facts.

Finally, when the subject is harmed because the experimenter negligently created a risk different from the one to which the subject assented, or is harmed by a risk the probability of occurrence of which was greatly increased by the experimenter's negligence, then the experimenter should be held liable where the magnitude of the resulting risk is disproportionate to the social utility of creating it.

Thus, tenability of assumption of risk in the secondary sense as a defense to negligently conducted experimentation is ultimately dependent upon policy considerations.

It would seem, then, in the light of this analysis of the question of liability, that concern for the position of the nontherapy-oriented experimenter ${ }^{30}$ and the research center, which is not at least a recognized therapeutic adjunct of a medical care and observation center, ${ }^{31}$ is especially warranted.

\section{Damages}

If it is assumed that the subject has established his right to have reparation for his injury, the law of damages will have a bearing on

\footnotetext{
${ }^{29}$ If the subject acted unreasonably in failing to appreciate the nature and extent of the risk, he ought to be barred by his inadvertent contributory negligence.

${ }^{30}$ Bressler, Silverman, Cohen \& Shmavonian, supra note 1 , at 526 .

${ }^{32}$ Ladimer, at 97.
} 
what types of harms are compensable. ${ }^{32}$ Writers who have considered the problem generally conclude that the difficulties of proof which would confront a court in a case involving both psychic injury and psychic stimulus are not insurmountable. ${ }^{33}$ Despite the existence of the elements of liability, damages may be labelled "remote" and compensation denied therefor as a result of restrictions which include the purely arbitrary. ${ }^{34}$ These restrictions have been outlined as difficulties of proof and judicial aversion to making the load of liability inordinately heavy. ${ }^{35}$

With respect to the first restriction, difficulties of proof would not be great in most cases of psychological experimentation, because evidence of the subject's pre-existing personality make-up, the force of the stimulus, and the susceptibility of the subject to the stimulus would probably be available. ${ }^{36}$ Thus, there would be a basis for comparing the subject's condition before and after the experiment, thereby obviating difficulties of proof present in the more common psychic injury-psychic stimulus case. A more exact basis for determining the extent of the injury is available.

Concerning judicial aversion to making the burden of liability too great, policy considerations similar to those which determine the existence of privilege would be relied upon. For example, this may involve an assessment of the possible deterrent effect of this additional cost factor upon the availability of funds for needed research.

\section{The Dilemma and Its Resolution}

Within an analytical framework such as this, then, the first human experimentation case may be decided, and a hitherto unaccounted-for element of the true cost of such experimentation distributed. Such an extension of the law, however, will not resolve the dilemma of society's needing research while at the same time requiring due legal protection for both experimenter and subject.

\footnotetext{
${ }^{83}$ Smith, Relation of Emotions to Injury and Disease: Legal Liability for Psychic Stimuli, 30 VA. L. REv. I 93, 252 (1944).

${ }^{33}$ Ibid.; McNiece, Psychic Injury and Tort Liability in New York, 24 ST. JoHN's L. REv. I (1949); Smith, Medical Evidence in Industrial Injury Cases with Special Reference to Neuropsychiatric Claims, in Workmen's Compensation Problems, II, 49 ( 67 U.S. DEP'T of LABOR BuLL. 1953); Smith \& Bradford, Medicolegal Aspects of Craniocerebral Injuries, 3 J. PUB. L. 663 (I954); Worden, Some Neglected Aspects of Injury, Mental Anguish and the Concept of Psychic Damage, 3 J. PUB. L. 377 (1954); Report of the New York State Law Revision Commission, Study Relating to Injuries Resulting from Fright or Shock, LEG. Doc. No. 65(E) (1936).

${ }^{84}$ Smith \& Solomon, Traumatic Neuroses in Court, 30 VA. L. REv. 87, 102 (1943).

${ }^{30} \mathrm{Id}$. at 105 .

${ }^{88}$ In his discussion of psychic injury and tort liability, McNiece states that recovery depends on these three factors. See McNiece, supra note 33, at 74 .
} 
The resolution of this dilemma can be premised upon the recognition that society is more than the ultimate beneficiary of research; through governmental action, society is the initiator of most research ${ }^{37}$ This condition alone, it would seem, should justify the following:

(I) A policy of liability without fault should be evolved for harm resulting from psychological experimentation. ${ }^{38}$

(2) Where the government undertakes or participates in the research program, it should also assume the burden of making injured subjects whole, through treatment and rehabilitation and by the payment of monetary compensation.

(3) The government should consider such an underwriting program as would be required to assume costs to subjects taking part in private research programs conducted under modern, controlled conditions. ${ }^{39}$

Among the effects of such developments on the whole environment of psychological experimentation would be compensation of the injured subject without regard to the doubtful questions of liability and proof of injury,,$^{40}$ thereby encouraging the participation of a sufficient number of subjects of varying levels of personality integration.

Further, there would also be legal protection for the experimenter who is part of an approved modern, controlled research program, thus encouraging research conducted on high planes. On the other hand, experimenters not of this class-those who are not associated with approved modern, controlled research programs-would be strictly liable for any harm which results from their inducing others to serve as subjects of their "research." Admittedly, the effect may be to discourage to some extent research which is not specifically socially sanctioned.

Finally, national research effort in this area would become more ordered in the sense and to the extent that the essentiality of each research program, as balanced against the program's total cost, would be the basis for go-ahead decisions by agencies having in view the entire research picture.

\footnotetext{
${ }^{37}$ See note 4 supra.

${ }^{38}$ 'Indeed, it is possible that a doctrine of liability without fault may be imposed, on the theory of a social cost of medical research, resembling concepts supporting programs such as workman's compensation." Ladimer, at 153 .

${ }^{39}$ See note I 8 supra.

${ }^{10}$ Remaining, however, would be the determination of the amount of recovery to be allowed, an admittedly difficult process in cases of altered psychologic functioning.
} 